\title{
THE ESTIMATION OF THE STRUCTURAL ELEMENTS OF CONDUCTIVITY OF THE VACUUM SYSTEM OF A PORTABLE MILKING MACHINE
}

\begin{abstract}
Jonas Č́̇̇NA, Aleksandras Stulginskis University, Faculty of Agricultural Engineering. Address: Studentu str. 15, LT-53362 Akademija Kauno r., Lithuania, jonas.cesna@asu.lt (corresponding author)

Oleksandr MEDVEDSKYI, Zhytomyr National Agroecological University, Faculty of Engineering and Energy, candidate of engineering science. Address: Staryi Blvd. 7, UA-10008, Zhytomyr, Ukraine, aleksmedvedsky@gmail.com

Gennadii GOLUB, National University of Life and Environmental Sciences of Ukraine, Tractors, Automobiles and Bioenergosistem Department, doctor of engineering science. Address: Heroyiv Oborony str., 15, UA-03041 Kyiv, Ukraine, gagolub@ukr.net Saveliy KUKHARETS, Zhytomyr National Agroecological University, Faculty of Engineering and Energy, doctor of engineering science. Address: Staryi Blvd. 7, UA-10008, Zhytomyr, Ukraine, saveliy 76@ukr.net

When designing the structural and functional schemes of the vacuum systems of a portable milking machine it is important to conduct a research on the impact on the milking machine efficiency. The technological efficiency and the regime of a vacuum system functioning are the basis of the research. The unstable pressure may cause the decrease in animals productivity and may have negative impact on cows welfare. That is why it is necessary to determine some rational parameters and choose the linking vacuum system decisions. It will result in getting stable working regimes of a portable milking machine. A research on the effects of different components variants as well as of vacuum system parameters on the consistency of operation has been conducted. The results of the research made it possible to estimate the impact of vacuum pump fast reaction as well as the vacuum system parameters on the job stability. It has been proved that the vacuum system efficiency is determined by the level of its conductivity. The conductivity is the inverse value to the vacuum system resistance. The research has determined how the vacuum system packaging affects the pressure loses. A mathematic model which enables to find the rational volume of a vacuum tank and determine the vacuum system conductivity has been received. On the results of the experimental research the vacuum system rational structure has been substantiated and estimated on a special efficiency coefficient.
\end{abstract}

Keywords: packaging, efficiency coefficient, gob stability, structural and functional scheme

\section{INTRODUCTION}

More than $70 \%$ of milk in Ukraine is produced by private farms (State Statistics, 2017). It is impossible to have a high quality milk without using an adapted system of cows milking (Mazur et al., 2006). The choice of mobile milking machines is expedient as they have a high service life and lower energy consumption (Revenko and Medvedskyi, 2010). Herewith, different construction schemes and a set of structural elements of the vacuum system are offered. But the impact of linking decisions as well as of technological parameters of the vacuum system in a mobile milking machine on milking efficiency have not been properly studied.

The quality of biotechnological process- machine milking- depends on the efficient vacuum system functioning. The vacuum level and the stability affect the animals state as well as the process efficiency (Besier and Bruckmaier, 2016). It has been proved (Kartashov, 1982) that systematic pressure fluctuation results in $9.2 \%$ decrease in productivity, as well as in milk fat level by $14 \%$. The level of cow diseases increases as well (Smoliar, 2014; Graeme, 2012). There is an effect of "ballonization" of the milking apparatus rubber, that causes milking glasses falling. Herewith, the pressure on the vacuum pump as well as on the support system of a stable pressure increases. The delay in job and a long period of stabilization result in the decrease of milking efficiency as a whole (Strobel et al., 2014).

The problem of pressure stabilization for stalled milking machines is offered to be solved by the volume increase in pulse tube lines as well as by raising the vacuum pump power. But mobile milking machines have mass and size limitations. At present there are no scientifically substantiated constructive and technological parameters of mobile milking machines. That is why the producers are governed only by logical supposition based on the analogy with stationary milking systems. That is why it is necessary to determine the effects of the constructive and technological parameters of vacuum system components on the vacuum pressure stability.

Copyright (C) 2017 The Authors. Published by Aleksandras Stulginskis University. This is an open-access article distributed under the terms of the Creative Commons Attribution License (CC-BY 4.0), which permits unrestricted use, distribution, and reproduction in any medium, provided the original author and source are credited. 


\section{MATERIALS AND METHODS}

The mobile milking complexes were estimated (Medvedskyi, 2015) by means of the exploitation indexes. Such estimation was made by using a multi-criteria method. As a result, two potential schemes of mobile milking machines arranging with the same volume of vacuum systems were determined. Hereby, the variant without a vacuum cylinder significantly differed in a bigger pulse tube diameter.

Such approach does not take into account the impact of vacuum system parameters on the level of pressure fluctuation. An important constituent is a vacuum pump job and the number of milking apparatus. According to the research (Choice and Estimation...., 2002) the vacuum pump productivity must be not less than $10 \mathrm{~m}^{3}$ per hour in terms of one milking apparatus. But interconnection between the vacuum system volume and the vacuum pump productivity with pressure losses were not studied before.

Pressure loses and its stabilization are of great importance (Fryc, 2003; Nosal and Bilgery, 2004). According to ISO 5707 (1991), there is a dependence:

$$
p_{t}=\Delta p \times t
$$

where: $p_{t}$ - is a limiting amplitude-and-time parameter, $\mathrm{kPa} \times \mathrm{s} ; \Delta p$ - is vacuum pressure losses in a vacuum network, $\mathrm{kPa}$; $t-$ is the duration of a stabilization period, s.

The research (Medvedskyi, 2015) has determined the functional dependence of pressure fluctuations on the parameters of the vacuum system constituents. In this case, the equation (1) will be:

$$
p_{t}=p_{v} \cdot t \cdot \frac{V_{m}}{2 V_{c}} \leq 40 \mathrm{kPa} \cdot \mathrm{s},
$$

where: $p_{v}$ - is service pressure, $\mathrm{kPa} ; V_{m}-$ is a milking container volume, liter; $V_{c}-$ is a vacuum system volume, liter.

According to the equation (2) the vacuum system volume has great impact on pressure stability. That is why the vacuum systems of mobile milking complexes must be estimated according to biotechnological indexes. The paper authors offer to use the following indexes.

The systematic vacuum pump productivity:

$$
Q_{V}=\frac{Q_{p}}{V_{c}}
$$

where: $Q_{p}-$ is the vacuum pump productivity, $\mathrm{m}^{3}$ per hour.

The service productivity of the vacuum pump:

$$
Q_{n}=\frac{Q_{p}}{n},
$$

where: $n$ - is a number of milking apparatus, units.

The indexes correspondence to the bound accepted limits will have positive effects on the machine milking efficiency. That is why, these indexes must correspond to serial mobile milking complexes, regardless their brand and model. For example, the vacuum systems characteristics vary greatly (Fig. 1.).

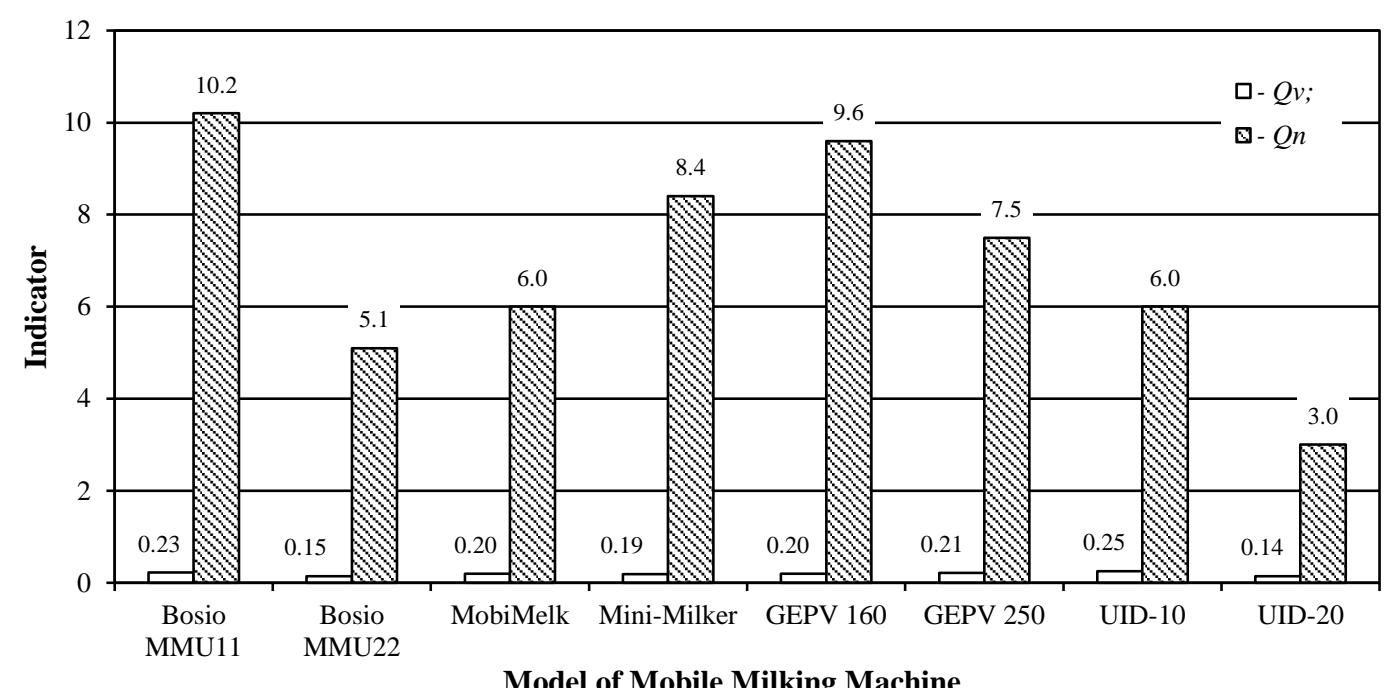

Figure 1. A compering diagram based on the technological indexes (authors research on the basis of accessible information on the technical characteristics of mobile milking complexes). 
There is significant difference between the models of mobile milking complexes on the indexes under research (Fig. 1). The analysis indicates at $44 \%$ dissimilarity on $Q_{v}$ index and $70.6 \%$ on index $Q_{n}$. Smaller indicators values belong to mobile complexes with two milking apparatus. A total vacuum systems volume is determined by the volume of a vacuum cylinder. Similar to linear milking complexes, foreign producers produce mobile milking apparatus with vacuum cylinders of greater volume. The mobile milking complexes of an Italian firm "Interpuls" have the biggest vacuum tank volume, and those of the firm "Bratslav" have the lowest volume under the same service productivity. Besides, the productivity of the vacuum pump of the complex UID is 40-60\% lower than that of the complex GEPV.

The introduction of different linking - as well as constructive and technological decisions as for mobile milking complexes is caused by the lack of scientifically substantiated recommendations. It can have negative effects on machine milking efficiency. In particular, the problem of minimization the fluctuations of vacuum pressure in a vacuum network is not solved.

The goal of the research is focused on the estimation of parameters effects of the vacuum system constituents in the mobile milking complex on the level and stability of a vacuum pressure. That is why it is necessary to determine the interrelation between the vacuum pump speed and the volume of the vacuum system constituents. The research methods are based on the application of Math simulation theory, the main laws of Hydro - and Gas Dynamics as well as of vacuum machines.

\section{RESULTS AND DISCUSSION}

The construction constituents of the vacuum system in the mobile milking complex resist the air flow. It causes pressure losses. It is practicable to decrease the losses by adapting the conductivity of the vacuum network to the vacuum pump productivity. Conductivity is a return value to the resistance of the air-carrying system, that is why a structural and functional schemes of a vacuum system are of great importance. Under the condition of the flow stability (Loytsianskiy, 2003) the pressure at the end of a vacuum- carrying net will be determined by its total conductivity (Pypko et al., 1988) Under the condition of gradual linking of the elements of the vacuum system it can be written:

$$
Q_{S}=\frac{1}{\sum_{i=1}^{n} \frac{1}{U_{i}}} \cdot\left(p_{2}-p_{1}\right)=U_{\Sigma} \cdot\left(p_{2}-p_{1}\right),
$$

where: $Q_{S}-$ is an air flow, $\mathrm{kPa} \times \mathrm{m}^{3} / \mathrm{s} ; U_{i}$ is the conductivity of the vacuum system element, $\mathrm{m}^{3} / \mathrm{s} ; U_{\Sigma}-$ is total vacuum system conductivity, $\mathrm{m}^{3} / \mathrm{s} ;\left(p_{2}-p_{1}\right)$ - is the difference in pressure at the end and at the beginning of the vacuum-carrying system, $\mathrm{kPa}$.

The main element of a vacuum system is a pipe connection. The improved formula (6) enables to determine the conductivity of any geometrical parameters as well as the exploitation conditions. (fig. 2):

$$
U_{\mathrm{p}}=85,5 \frac{d_{\mathrm{p}}^{4} \cdot \sqrt{T}}{l_{\mathrm{p}} \cdot b_{\varepsilon}} \cdot\left(\frac{p_{1}+p_{2}}{2}\right),
$$

where: $b_{\varepsilon}-$ is a temperature coefficient, $b_{\varepsilon}=1$ under air temperature $t=0^{\circ} \mathrm{C} ; l_{\mathrm{p}}-$ is the pipe connection length.

While specifying the dependences (Pypko et al., 1988; Frolov et al., 1992), a formula for determining the pressure at the end of the pipe connection:

$$
p_{2}=\sqrt{p_{1}^{2}+\frac{Q_{S} \cdot l_{p} \cdot b_{\varepsilon}}{42,75 \cdot d_{p}^{4} \cdot \sqrt{T}}}
$$

Local resistance in correspondence with recommendations (Idelchyk, 1992) is taken into account by means of increasing the pipe connection length by an equivalent constituent.

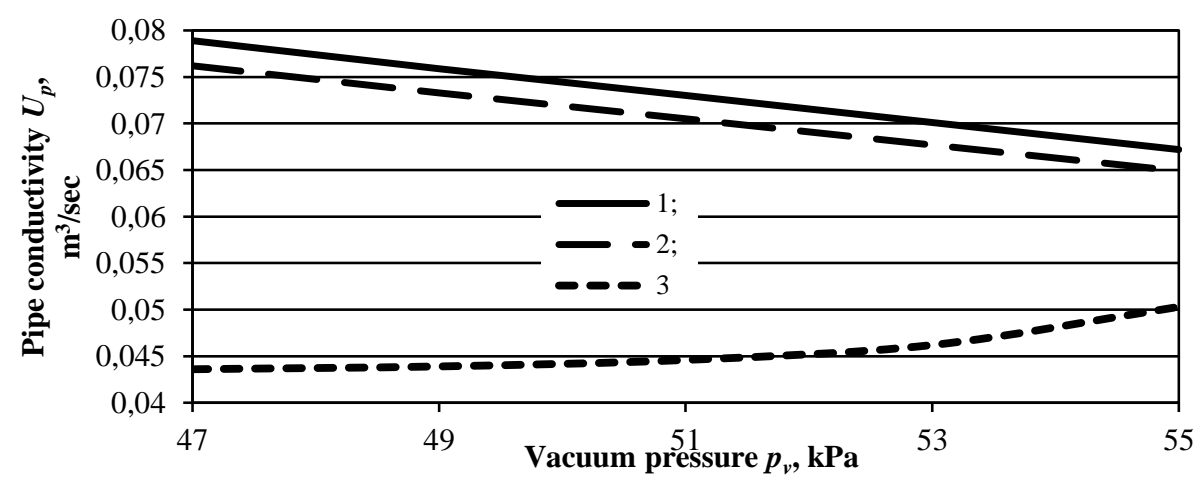

Figure 2 . The dependence of pipe connection conductivity on the vacuum pressure at a crosscut: $1-$ straight line pipe connection $l_{\mathrm{p}}$ length; 2 - a pipe connection $l_{\mathrm{p}}$ length bent at angle of $90^{\circ} ; 3-$ a short pipe connection $l_{\mathrm{p}}<20 d_{\mathrm{p}}$. 
The pipe connection conductivity $\left(U_{p}\right)$ depends on geometric parameters as well as on pressure level (fig. 2). Under the increase in the level of vacuum pressure the productivity of long pipe connections decreases owing to the decrease in the volume of air flow $\left(Q_{S}\right)$. The conductivity of the pipe connection which is bent at the angle of $90^{\circ}$ is $3.5 \%$ lower as compared to the straight line pipe connection of the same length. A short pipe connection $l_{\mathrm{p}}<20 d_{\mathrm{p}}$ long has a much lower conductivity, that does not change in a vacuum pressure range. The reason for it is a not sufficient length of a pipe connection for removing the air flow outbreaks.

The advantages of this kind of computing are vivid. It combines geometric peculiarities of linking as well as the vacuum pump productivity. The determination of the conductivity of the vacuum system elements needs only incoming information. A parallel linking of the constituent parts of the vacuum system can be more accepted owing to higher conductivity (Pypko et al., 1988).

$$
U_{\Sigma}=\sum_{i=1}^{n} U_{i} .
$$

A significant fall in vacuum pressure occurs at the moment of milking machine linking up. An efficient vacuum system service is characterized by minimal pressure fluctuations and by its fast stabilization. The problem can be solved by a rational correlation between the parameters of a vacuum system elements and the vacuum pump speed. A vacuum cylinder determines the volume of a vacuum net. The volume of a milk container forms the entire volume of vacuum system. Having taken into account the equation (2) and (5) we will get a formula for determining the vacuum tank volume:

$$
V_{b}=\frac{V_{m}^{2}\left(1-2 \cdot \frac{p_{t}}{t_{1} \cdot p_{v}}\right)}{4 \cdot Q_{S} \cdot p_{t}} \cdot p_{v}^{2}-V_{p},
$$

where: $V_{b}$ - is vacuum cylinder volume, $\mathrm{m}^{3} ; V_{m}$-is a milk container volume, $\mathrm{m}^{3} ; V_{p}$ - is the volume of vacuum carrying elements, $\mathrm{m}^{3} ; t_{1}-$ is a boundary length of the stabilization process, $\mathrm{s}$.

The volume of a gas container will depend on the air flow, which is created by a vacuum pump, as well as on the milk container volume under the pressure $p_{v}$ (fig. 3).

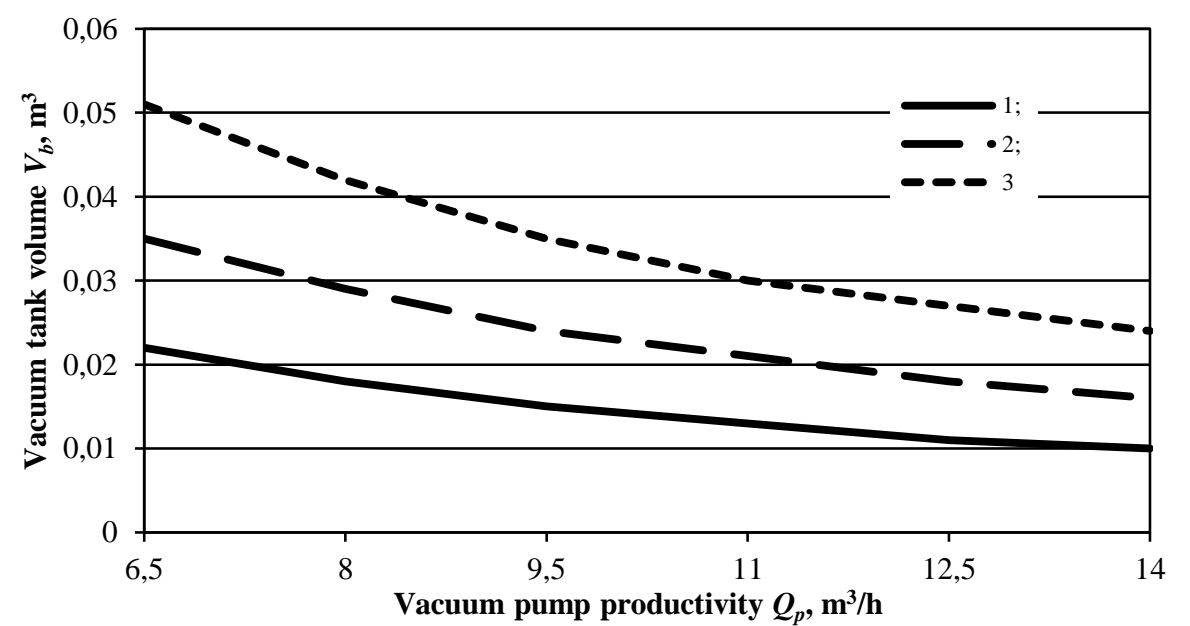

Figure 3. The dependence of the vacuum tank on the productivity of a vacuum pump and the milk container volume: $1-V_{m}=0.02 \mathrm{~m}^{3}$; $2-V_{m}=0.025 \mathrm{~m}^{3} ; 3-V_{m}=0.03 \mathrm{~m}^{3}$.

Graphical dependence in fig. 3 shows the interrelation between the geometric parameters of a vacuum system and the vacuum pump speed. The results of the research correspond to pressure $p_{v}=50 \mathrm{kPa}$ as well as to the limiting parameter of pressure fluctuation $p_{t}=40 \mathrm{kPa} \times \mathrm{S}$ under the condition of increasing the vacuum pump speed, the vacuum tank volume decreases according to the exponential law irrespective of the milk container volume. Under the condition of using a milk container $0.02 \mathrm{~m}^{3}$ in volume, the vacuum cylinder volume can be decreased by from $0.02 \mathrm{~m}^{3}$ to $0.01 \mathrm{~m}^{3}$ when the pump productivity increases by from $7.2 \mathrm{~m}^{3} / \mathrm{h}$ to $14 \mathrm{~m}^{3} / \mathrm{h}$. But, irrespective of the vacuum pump productivity, the bigger the volume of a milk container is, the bigger is the volume of a vacuum tank.

The scheme of joining the structural elements of a vacuum system affects its entire conductivity. The most common are successive and successive parallel joining. In this case they receive the schemes with a through or with a blind location of a vacuum cylinder. A total conductivity of a linking scheme is reversely proportional to the difference in pressure of final cross-cuts of a vacuum system:

$$
U_{\Sigma}=\frac{Q_{p} \cdot p_{p}}{\left(p_{2}-p_{1}\right)},
$$

where: $p_{p}-$ is pressure in a front cross-cut of a vacuum pump, $\mathrm{kPa}$. 
The pressure losses under the condition of stationary flow as well as of steady operation of a milking machine pulsator were studied experimentally. We used tensometric pressure sensors IPD-2-0.06, a comparison unit and a Topaz 3-0.2 amplifier, and a self-recording device N 3021-3. Different parameters of pressure losses in a pulse tube for different linking schemes were revealed. But comparing of an absolute value of pressure losses will not make it possible to find a rational linking scheme. To do it, we offer to use an efficiency coefficient $\left(k_{e}\right)$ :

$$
k_{e}=\frac{\Delta p_{1}}{\Delta p_{2}}=\frac{Q_{p 1} \cdot p_{p 1} \cdot U_{\Sigma 2}}{U_{\Sigma 1} \cdot Q_{p 2} \cdot p_{p 2}},
$$

where: $\Delta p_{1}$ - is pressure losses under stationary operating conditions, $\mathrm{kPa} ; \Delta p_{2}-$ is pressure losses under steady pulsator operation, $\mathrm{kPa} ; Q_{p 1}$ - is air losses under pressure in a cross-cut of a vacuum pump $p_{p 1}, \mathrm{~m}^{3} / \mathrm{s} ; Q_{p 2}-$ is air losses under pressure in a cross-cut of a vacuum pump $p_{p 2}, \mathrm{~m}^{3} / \mathrm{s} ; U_{\Sigma l}, U_{\Sigma^{2}}-$ is a total conductivity of a vacuum system under stationary operating conditions and a steady pulsator operation, $\mathrm{m}^{3} / \mathrm{s}$.

Structural and functional schemes of vacuum systems differ in the efficiency coefficient (fig. 4).

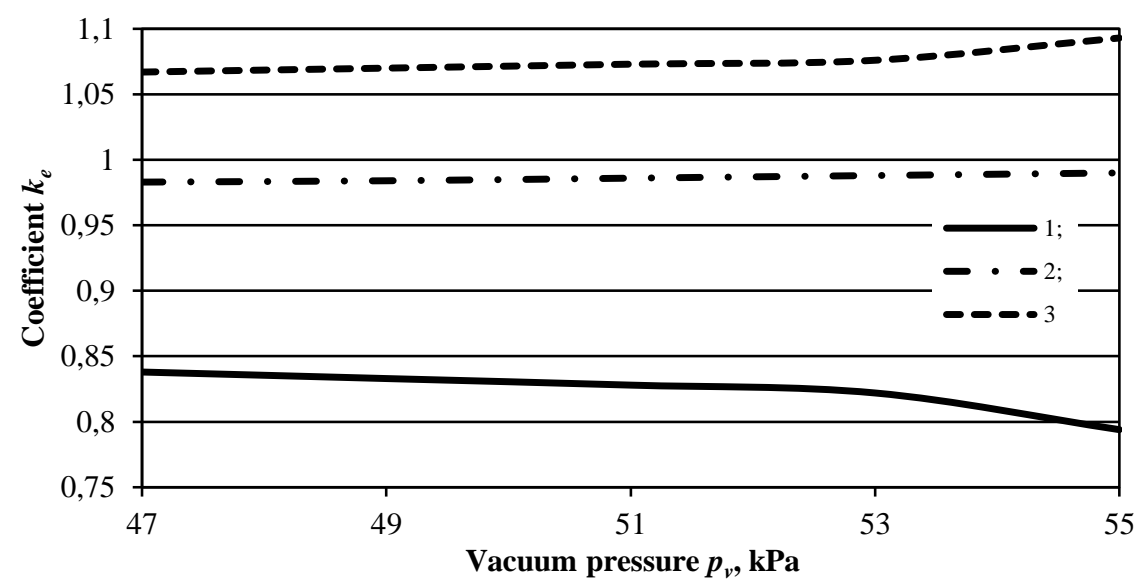

Figure 4. An efficiency coefficient of various linking schemes of a vacuum system: 1 - with a through vacuum tank; 2 - without a vacuum tank; 3 - with a vacuum tank at the end of a vacuum pulse tube.

The linking scheme with a blind location of a vacuum tank is estimated as the one which has the lowest losses. That is why the efficiency coefficient is of greatest importance $k_{e}=1.06-1.08$ within the vacuum pressure $p_{v}=47-53 \mathrm{kPa}$ (fig. 4). The efficiency coefficient of a linking scheme with a through vacuum tank is the lowest $-k_{e}=0.79-0.84$. It can be explained by higher pressure losses (by $5.2-6.5 \mathrm{kPa}$ ) at steady pulsator operation of the milking machine. The efficiency coefficient of the linking scheme without a vacuum tank is nearly $1\left(k_{e}=0.98\right)$. Such structural and functional scheme of the vacuum system is characterized by the same efficiency for the stationary working condition and steady operation of a milking machine pulsator.

\section{CONCLUSIONS}

1. Commercial mobile milking machines from different producers are different as for their biotechnological indexes. On the results of the research it has been determined that the vacuum system volume must be adapted to the vacuum pump speed. Besides, the vacuum cylinder volume must correspond to the milking container volume. It has been determined that by the bigger volume of a milk container it is necessary to increase the vacuum cylinder volume irrespective of the vacuum pump speed. Only under these conditions the pressure losses decrease and the fluctuations reduce. Thus, the mobile machine efficiency depends on rational and constructional parameters as well as on technological characteristics of the vacuum system constituents.

2. A quantitive comparable estimation of the efficiency of mobile milking machines is expedient to make by means of efficiency coefficient $\left(k_{e}\right)$. A structural and functional system of a vacuum system with a blind location of a vacuum cylinder is by $8.4-8.6 \%$ more efficient than without a vacuum cylinder. Besides, such linking requires a 8-11\% lower level of the initial vacuum pressure. The experimental research proved to the expedience of the vacuum regulator next to the branch pipe of the vacuum pump. Such a linking increases the efficiency of the structural and functional scheme with a through vacuum cylinder on account of higher system conductivity.

3. Thus, milking machines must be equipped with a vacuum tank of a corresponding volume and with a successive and parallel scheme of a vacuum system. It will increase the efficiency of biotechnological process of cow machine milking on account of steady operation of the performing mechanisms.

\section{REFERENCES}

1. Besier, J., Bruckmaier, R. 2016. Vacuum levels and milk-flow-dependent vacuum drops affect machine milking performance and teat condition in dairy cows. Journal of Dairy Science, Vol. 99, Iss. 4, pp. 3096-3102. 
2. Choice and Estimation of Milking Machines and Small Vacuum Systems: Guidelines. 2002. Harkov, 84 p.

3. Frolov, S., Minaychev, V., Aleksandrova, A. 1992. Vacuum Machinery.reference book. Machine building, Moscow.

4. Fryč, J. 2003. Comparison of the operation of milking machine control valves and a newly designed regulating device. Research in Agricultural Engineering, Vol. 49, pp. 110-114.

5. Graeme, A. 2012. The Role of the Milking Machine in Mastitis Control. Veterinary Clinics of North America: Food Animal Practice, Vol. 28, Iss. 2, pp. 307-320.

6. Idelchyk, I. 1992. Reference book on hydrolic resistances. 3 rd. ed., Machine building, Moscow. [In Russian]

7. ISO 5707: 1983. 1991.Milking Machines. Construction and Technical Characteristics. Standards Publishing House, Moscow. [In Russian]

8. Kartashov, L. 1982. Machine milking of cows. Kolos, Moscow. [In Russian]

9. Loitsianskiy, L. 2003. Mechanics of Liquid and Gas, 7 rd.ed., Drofa, Moscow. [In Russian]

10. Mazur, T., Ocheretiana, L., Dyman, T. 2006. The Row Milk Ecology at the Households of different Ownership Forms. Animal Hasbendry in Ukraine, Vol. 4, pp. 7-8.

11. Medvedskyi, A. 2015. The impact of the Constructive parameters of a mobile milking machine on the level of vacuum pressure. Motrol. Commission of Motorization and Energetics in Agriculture, Vol.17, Iss 3, pp. 250-257.

12. Nosal, D., Bilgery, E. 2004. Airborne noise, structure-borne sound (vibration) and vacuum stability of milking systems. Czech Journal of Animal Science, Vol. 49, pp. 226-230.

13. Pipko, A., Pliscovskiy, V., Penchko, E. 1988. Technical grounds of Vacuum Machinery. Energy Publishing house, Moscow. [In Russian]

14. Revenko, I., Medvedskyi, O. 2010. The perspectives of Milking Mechanization on Small Farms. National Bulletin of the National University of Bioresources and Land Management of Ukraine: Machinery and Power Economy of AIC, Vol, 144, Iss 4, pp. 82-87.

15. Smoliar, V. 2014. The Level of Garget Occurrence in Cows when Applying Different Types of Milking Machines. Machinery and Technologies of AIC, Vol. 148, pp. 17-20.

16. State Committee of Statistics of Ukraine. 2017. The Production of Basic Types of Animal Produce. Available at http://www.ukrstat.gov.ua [In Russian]

17. Ströbel, U., Rose-Meierhöfer, R., Brunsch, R. 2014. Design of a vacuum control system with frequent teat-end vacuum adaption for milking machines. Proceedings International Conference of Agricultural Engineering, Zurich, pp. 1-6. 